\title{
Esophageal diverticulosis
}

Karina Witkiewicz, Janusz Wójcik, Jarosław Pieróg, Norbert Wójcik, Bogumił Maciąg, Tomasz Grodzki

General Thoracic Surgery and Transplantation Department, Pomeranian Medical University, Szczecin, Poland

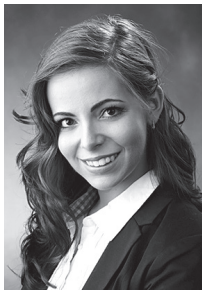

Kardiochirurgia i Torakochirurgia Polska 2017; 14 (2): 146-147

Esophageal diverticula occur with a frequency of $2 / 100,000 /$ year. The most common location of acquired single diverticula is the cervical part of the esophagus, which mainly concerns patients in the $7^{\text {th }}$ decade of life [1]. Multiple diverticula of the middle part of the esophagus are a rare condition and occur with a frequency of $1 / 500,000$ / year [2].

A 49-old-year woman was admitted to the hospital due to solid food dysphagia associated with retrosternal pain, malnutrition and loss of $8 \mathrm{~kg}$ of weight during the last year. Her weight was $47 \mathrm{~kg}$ and body mass index (BMI) $19.56 \mathrm{~kg} / \mathrm{m}^{2}$ at the time of admittance. The symptoms of the disease had been developing gradually for a few years. Diverticulosis of the thoracic part of the esophagus had been confirmed endoscopically 3 years ago before hospitalization. She had received steroids for a long time due to systemic lupus erythematosus (SLE). The steroid treatment was complicated with side effects such as osteoporosis and loss of menstruation at the age of 39 years. Attempts of abundant drinking did not improve swallowing in spite of lack of structural stenosis confirmed in endoscopy examination. It was decided to perform subtotal minimally invasive esophagectomy (laparoscopy with right videothoracoscopy-VATS and cervicotomy) (Figs. 1, 2). The
VATS procedure was performed in the prone position. The postoperative period was uneventful with full restoration of swallowing. A histopathologic specimen of the resected esophagus confirmed chronic inflammatory changes in the multiple diverticula walls of the resected esophagus.

Single diverticula of the cervical and epiphrenic part of the esophagus arise by a "pushing mechanism" whereas diverticula at the level of the tracheal bifurcation arise by a "pulling mechanism" [3, 4]. Disorders of esophageal motility, diffuse esophageal spasm and achalasia are the base of arising multiple diverticula or diverticulosis in the thoracic part of the esophagus $[5,6]$. There is no relationship between SLE and esophageal motility disorders and diverticulosis reported in the literature; however, it would have been strongly associated in the present case. This theory would be confirmed by absence of stenosis in the endoscopic examination. Exacerbation of clinical symptoms as dysphagia, pain, malnutrition, and food retention depends on the shape and size of the diverticula. The seven diverticula were confirmed in the case, but five of them with a multicentimeter size made food retention much stronger. Minimally invasive esophagectomy (laparoscopy with VATS and cervicotomy) with cervical gastro-esophageal anastomosis allowed the patient to be restored to a good quality
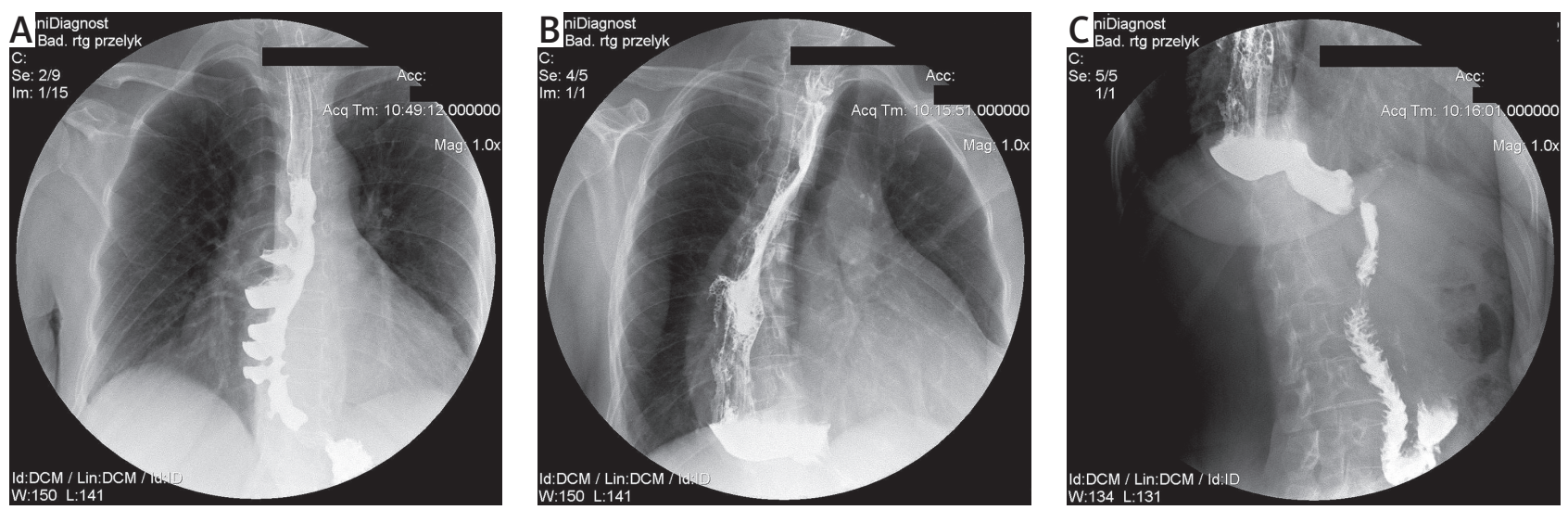

Fig. 1. X-ray contrast examination. A - Preoperative view. Numerous diverticula in the middle and lower thoracic part of the esophagus are visible. B - Postoperative view. Esophagus replaced by gastric graft. Gastro-esophageal anastomosis at the level of his collarbone. C - Postoperative view. Lower part of the gastric graft and duodenum located in the vertical position. Pylorus at the hiatal level

Address for correspondence: Janusz Wójcik MD, General Thoracic Surgery and Transplantation Department, Pomeranian Medical University, 11 Sokołowskiego St, 70-891 Szczecin, Poland, phone: +48 509501 716, fax: +48 914620 836, e-mail: janusz.zenon.wojcik@wp.pl Received: 26.05.2016, accepted: 17.11.2016. 


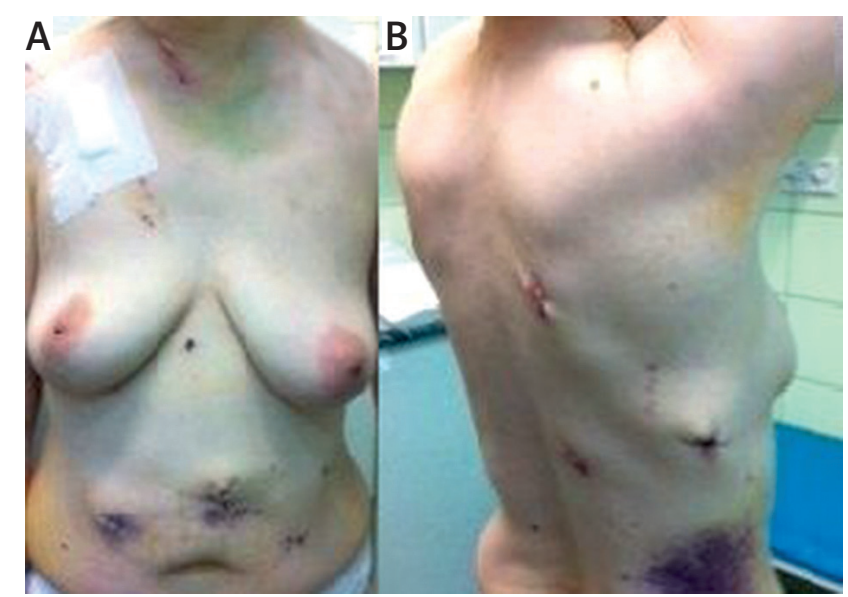

Fig. 2. View of operative accesses of the minimally invasive esophagectomy. A - Front view. Five laparoscopic accesses and right sided oblique cervicotomy. B - Posterior view. Three accesses of the right VATS. Lower anterior access was used to insert a drain tube into the right pleural space

of life. This patient is the second multiple esophageal diverticula case in our material [7]. The first patient was affected by multiple esophageal diverticula of the cervical part of the esophagus and treated by surgery with a good result; therefore, surgery seems to be the treatment of choice in such cases [8-10].

\section{Disclosure}

Authors report no conflict of interest.

\section{References}

1. Bizzotto A, lacopini F, Landi R, Costamagna G. Zenker's diverticulum: exploring treatment options. Acta Otorhinolaryngol Ital 2013; 33: 219-229.

2. Abdollahimohammad A, Masinaeinezhad N, Firouzkouhi M. Epiphrenic esophageal diverticula. J Res Med Sci 2014; 19: 795-797.

3. Herbella FA, Patti MG. Achalasia and epiphrenic diverticulum. World J Surg 2015; 39: 1620-1624.

4. Smith C. Esophageal strictures and diverticula. Surg Clin North Am 2015; 95: 669-681.

5. Matsumoto H, Kubota H, Higashida M, Manabe N, Haruma K, Hirai T. Esophageal epiphrenic diverticulum associated with diffuse esophageal spasm. Int J Surg Case Rep 2015; 13: 79-83.

6. Tamura Y, Funaki Y, Adachi K, Noda H, Izawa S, lida A, Ogasawara N, Miyaji M, Sasaki M, Kasugai K. A patient with vigorous achalasia and rapid enlargement of an epiphrenic esophageal diverticulum. Intern Med 2015; 54: 1609-1612.

7. Wójcik J, Grodzki T, Stankiewicz D, Janowski H, Kochanowski L, Alchimowicz J, Kubisa B, Pieróg J, Kozak A. Multiple diverticula of cervical part of esophagus. Pol J Thorac Cardiovasc Surg 2005; 2: 74-78.

8. Hauge T, Johnson E, Sandstad O, Johannessen HO, Trondsen E. Surgical treatment of epiphrenic oesophageal diverticulum. Tidsskr Nor Laegeforen 2014; 134: 1047-1050.

9. Orringer MB, Orringer JS. Esophagectomy: definitive treatment for esophageal neuromotor dysfunction. Ann Thorac Surg 1982; 34: 237-248.

10. Young MM, Deschamps C, Trastek VF, Allen MS, Miller DL, Schleck CD, Pairolero PC. Esophageal reconstruction for benign disease: early morbidity, mortality, and functional results. Ann Thorac Surg 2000; 70: 1651-1655. 